\title{
Human Cytomegalovirus Increases Modified Low Density Lipoprotein Uptake and Scavenger Receptor mRNA Expression in Vascular Smooth Muscle Cells
}

\author{
Yi Fu Zhou, Esther Guetta, Zu Xi Yu, Toren Finkel, and Stephen E. Epstein \\ Cardiology Branch, National Heart, Lung, and Blood Institute, National Institutes of Health, Bethesda, Maryland 20892
}

\begin{abstract}
Evidence suggests a possible role for human cytomegalovirus (HCMV) in the development of arteriosclerosis. One of the earliest events in plaque formation is the accumulation of lipid-laden foam cells, derived from macrophages and smooth muscle cells (SMCs). The lipid accumulation that occurs depends upon the uptake of oxidized LDL (OxLDL), a process in which the scavenger receptor (SR) has been postulated to play an important role. We therefore examined the effects of HCMV on this process. We demonstrate that HCMV infection of human SMCs increases modified LDL uptake and stimulates class A SR gene (SR-A) mRNA expression. In addition, infection of rat SMCs with HCMV, which causes immediate early gene expression (IE72/IE84), but no early or late HCMV gene products and no cytopathic effects, also increases SMC uptake of Ox-LDL and acetylated LDL, with either effect blocked by an excess of either cold Ox-LDL or acetylated-LDL, and by fucoidin, an SR competitor. Cotransfection of an IE72, but not an IE84, expression plasmid and a plasmid containing a Class A SR promoter/reporter gene construct enhances SR promoter activity. Since increased Ox-LDL uptake is believed to play an important role in arteriosclerosis, these results provide a link between HCMV infection and arteriosclerotic plaque formation. (J. Clin. Invest. 1996. 98:2129-2138.) Key words: atherosclerosis $\bullet$ transfection - reverse transcriptase polymerase chain reaction $\bullet$ immediate-early genes $\bullet$ immunohistochemistry
\end{abstract}

\section{Introduction}

Several lines of evidence suggest that infection with human cytomegalovirus (HCMV), ${ }^{1}$ a herpesvirus, may play a role in

Address correspondence to Stephen E. Epstein, Building 10, 7B15, 10 Center Drive MSC 1650, National Institutes of Health, Bethesda, MD 20892-1650. Phone: 301-496-5817; FAX: 301-402-0888.

Received for publication 14 December 1995 and accepted in revised form 5 September 1996.

1. Abbreviations used in this paper: Ac-LDL, acetylated LDL; CPE, cytopathic effect; DiI-Ac-LDL, 1,1'-dioctadecyl-3,3,3',3'-tetramethylindocarbocyanine perchlorate; HCMV, human cytomegalovirus; HGH, human growth hormone; IE, immediate early; Ox-LDL, oxidized LDL; RT-PCR, reverse transcriptase PCR; SMC, smooth muscle cell; SR, scavenger receptor; SR-A, class A SR gene products (types I and II).

The Journal of Clinical Investigation

Volume 98, Number 9, November 1996, 2129-2138 the development of atherosclerosis. For example, HCMV is widely distributed in the population in an age-related pattern similar to that of atherosclerosis, HCMV DNA sequences have been detected in the wall of atherosclerotic vessels, and accelerated coronary atherosclerosis is much more common in cardiac transplant patients exposed to HCMV than in those who have had no such exposure (1-7). Moreover, atherosclerotic lesions develop in chickens infected with Marek's disease virus, an avian herpesvirus $(8,9)$.

Lipid accumulation is one of the critical mechanisms contributing to atherogenesis, and it has been shown that Marek's disease virus induces cholesterol accumulation in the aorta of infected animals. A virus-induced defect in the enzyme responsible for esterifying free cholesterol was thought to contribute to this effect $(10,11)$.

The importance of lipids in initiating the atherosclerotic process is exemplified by the characteristic feature of the earliest lesion of atherosclerosis, accumulation of lipid-laden foam cells, which are derived from macrophages and smooth muscle cells (SMCs) (12). Native LDL does not in itself predispose to foam cell development, in part because its receptor, the LDL receptor, downregulates in response to increasing intracellular levels of LDL $(13,14)$. LDL, however, is oxidized in the subintimal space to oxidized LDL (Ox-LDL), which is transported into the cell via the scavenger receptor (SR) $(12,15)$. Most importantly, this receptor, unlike the LDL receptor, does not downregulate as intracellular cholesterol levels rise, thereby providing a mechanism for large amounts of cholesterol to accumulate (16). This presumably leads to the development of foam cells and thereby may contribute to the atherosclerosis process (17-20).

It was therefore the purpose of the present investigation to determine whether HCMV possesses the genetic program to induce molecular alterations in its host cell that might contribute to the lipid component of atherogenesis. Specifically, we investigated $(a)$ whether HCMV infection of SMCs increases Ox-LDL accumulation; and, if so, $(b)$ whether this effect can be induced by expression of HCMV's immediate-early (IE) gene products in the absence of viral replication (as would occur with an abortive, as opposed to a permissive, HCMV infection); and (c) whether this effect is associated with and caused by increased SMC scavenger receptor expression.

\section{Methods}

Cell culture. Primary human aortic smooth muscle cells were obtained from Clonetics Corp. (San Diego, CA). Cells were maintained in SmGM2 (smooth muscle growth medium, supplemented with 5\% fetal bovine serum, $10 \mathrm{ng} / \mathrm{ml}$ human epidermal growth factor, and 2.0 $\mathrm{ng} / \mathrm{ml}$ human fibroblast growth factor) and used from passage 3-5. Passage 3-10 primary rat aortic smooth muscle cells were isolated and cultured as previously described (21). Their identity was confirmed by the typical morphology of slight "hill and valley" arrangement and by positive fluorescent staining with antimuscle $\alpha$-actin an- 
tibody. Human embryonic lung fibroblast cell line (HEL-299), THP-1 cell line, and HeLa cells were obtained from American Type Culture Collection (Rockville, MD); primary human peripheral monocytes were separated by Ficoll-Hypaque sedimentation method from fresh heparinized blood of normal donors and incubated for $2 \mathrm{~h}$ at $37^{\circ} \mathrm{C}$ in $5 \% \mathrm{CO}_{2}$. Nonadherent cells were removed by three washes with PBS (22). Adherent cells were then cultured for $10 \mathrm{~d}$ with RPMI 1640 supplemented with $10 \% \mathrm{FBS}$ and $30 \mathrm{ng} / \mathrm{ml}$ monocyte-colony stimulate factor (Sigma Chemical Co., St. Louis, MO).

Virus. Towne strain HCMV was obtained from American Type Culture Collection and was propagated on passage 8-20 HEL-299 cells in an MOI of 0.01 for virus stock. Briefly, 70-90\% confluent HEL-299 cells were inoculated with HCMV for $2 \mathrm{~h}$, with rocking every 15 min. After HCMV adsorption, the inoculum was aspirated and cells were washed twice with serum free medium, then refed with growth medium (containing 10\% FBS). HCMV-infected monolayers were observed daily by inverted light microscopy for cytopathic effect (CPE). 3-7 d later, when the cells reached 100\% CPE, the medium was collected and centrifuged to remove cell debris. The supernatant was collected and stored at $-80^{\circ} \mathrm{C}$ as the viral stock. The titer of HCMV stock was determined by standard $\operatorname{TCID}_{50}(50 \%$ tissue culture infective doses) assay (23).

Acetylated LDL (Ac-LDL) uptake by human aortic smooth muscle cells. To determine whether HCMV infection increases uptake of modified LDL by SMCs, human aortic SMCs ( $80 \%$ confluent) were infected with HCMV at 5 MOI. On day 4 after infection, the cells were incubated for $4 \mathrm{~h}$ in normal growth medium supplemented with $5 \mu \mathrm{g} / \mathrm{ml}$ acetylated low density lipoprotein, which was fluorescently labeled with 1,1'-dioctadecyl-3,3,3',3'-tetramethylindocarbocyanine perchlorate (DiI-Ac-LDL; Biomedical Technologies, Inc., Stoughton, MA), and then washed three times with media and once with PBS, followed by fixation in freshly made $4 \%$ paraformaldehyde/PBS for $20 \mathrm{~min}$ at room temperature. Cells were then rinsed for $5 \mathrm{~s}$ in distilled water, drained, and mounted with $90 \%$ glycerol and $10 \%$ PBS. SMC uptake of DiI-Ac-LDL was analyzed by fluorescence microscopy using standard rhodamine excitation. A similar procedure was used for rat SMCs infected with HCMV, except that a higher MOI (200) was used for the initial infection.

Determination of scavenger receptor $m R N A$ expression by reverse transcriptase PCR after HCMV infection. Human aortic SMCs, at $\sim 80 \%$ confluence, were infected with HCMV at 1, 5, and 10 MOI. $4 \mathrm{~d}$ later, total RNA was isolated by using RNAzol ${ }^{\mathrm{TM}} \mathrm{B}$ (Biotecx Laboratories Inc., Houston, TX) according to the manufacturer's recommendations. The isolated RNA $(1 \mu \mathrm{g})$ was used as a template for reverse transcriptase PCR (RT-PCR; Perkin-Elmer Corp., Norwalk, CT), using either random primers or a specific $3^{\prime}$ scavenger receptor (class A, types I and II) primer (SR2). The cDNA produced was used for two rounds ( 35 cycles each) of the polymerase chain reaction using sets of nested primers from the known sequence of the human scavenger receptor gene (24). Primer set 1: SR1-5'> ATG GAG CAG TGG GAT CAC TT $<3^{\prime}$, SR2 $-5^{\prime}>$ GGA GGA CCT TGA ATT AAA GT < 3'; primer set 2: SR3-5'> GAC ACT GAT AGC TGC TCC GA, SR4-5' > AAT GTT CCC AAT CTT TCA GT $<3^{\prime}$. The predicted amplified product is $700 \mathrm{bp}$. As a positive control, RNA was isolated in parallel from the THP-1 cell monocytic line stimulated with 12-O-tetradecanoylphorbol-13-acetate, which induces scavenger receptor expression (25), and from differentiated human peripheral monocytes.

Immunohistochemical analysis of IE gene expression of HCMVinfected rat SMCs. Primary cultured rat SMCs were seeded and cultured in eight-well chamber glass slides for 3-5 d before infection with HCMV (200 MOI). Cells were exposed to virus in serum free medium. $2 \mathrm{~h}$ after viral inoculation, the cells were washed twice with serum free medium and then returned to normal growth medium. The infected and noninfected control rat SMCs were checked for HCMV antigen expression at day 1, 2, 3, 5, 7, 9, and 11 after HCMV inoculation by using standard immunoperoxidase staining. Briefly, eight-well chamber slides of infected or uninfected cells were fixed with acetone for $5 \mathrm{~min}$ at room temperature, transferred to TBS $(\mathrm{pH}$ 7.6), and then immersed in 5\% normal horse serum in buffer for 20 min. Primary monoclonal antibodies to HCMV IE72 and IE84 (Vancouver Biotech, Vancouver, Canada) were used at a concentration of $1 \mu \mathrm{g} / \mathrm{ml}$. After incubation in a moist chamber at room temperature for $1 \mathrm{~h}$, the slides were washed in TBS and biotinylated goat antimouse IgG secondary antibody (Vector Laboratories, Burlingame, CA) was added. After a 1-h incubation in a moist chamber, the slides were washed in TBS, overlaid for 45 min with avidin-biotin-peroxidase, washed again in TBS, and developed in DAB solution. Slides were counterstained with $1 \%$ methyl green (in $0.1 \mathrm{M}$ sodium acetate, $\mathrm{pH} 4.0$ ) for $10 \mathrm{~min}$ before routine dehydration and mounting.

To determine whether the cells that took up acetylated LDL were the same cells that expressed the IE gene products of HCMV, we performed colocalization immunohistochemistry. $4 \mathrm{~h}$ after incubation with DiI-Ac-LDL, the cells were washed three times with media and fixed with $4 \%$ formaldehyde/PBS for $10 \mathrm{~min}$ at room temperature. After fixation, cells were washed three times with PBS, and then immersed for $20 \mathrm{~min}$ in PBS supplemented with 5\% normal horse serum. Antibody to IE72 (Vancouver Biotech) at $10 \mu \mathrm{g} / \mathrm{ml}$ was added for a 1-h incubation in a moist chamber at room temperature. Slides were then washed in PBS and an FITC-conjugated horse anti-mouse IgG antibody (Vector Laboratories, Inc.) at 1:50 dilution was added for $1 \mathrm{~h}$. Slides were then washed in PBS and mounted with AquaPoly/Mount (Polysciences Inc., Warrington, PA).

Quantification of ${ }^{125} I-O x-L D L$ and ${ }^{125} I-A c-L D L$ uptake. To quantify HCMV-mediated effects on scavenger receptor activity, ${ }^{125} \mathrm{I}-$ labeled oxidized LDL and ${ }^{125}$ I-labeled acetylated LDL (Biomedical Technologies, Inc.) was incubated with either infected or noninfected rat SMCs. Human LDL was oxidized using $5 \mu \mathrm{M} \mathrm{Cu}_{2} \mathrm{SO}_{4}$ in PBS at $37^{\circ} \mathrm{C}$ for $24 \mathrm{~h}$. The reaction was terminated by adding EDTA to achieve a concentration of $50 \mu \mathrm{M}$. Ox-LDL was subsequently dialyzed overnight in TBS with $0.3 \mathrm{mM}$ EDTA. Human LDL was acetylated with acetic anhydride at 1.5 times the protein weight of LDL. Ac-LDL was then purified by agarose gel electrophoresis. Both OxLDL and Ac-LDL were ${ }^{125}$ I labeled by the Iodine Monochloride method to a specific activity of 0.134 and $0.143 \mu \mathrm{Ci} / \mu \mathrm{g}$, respectively. Cells were seeded and cultured in six-well culture plates and infected with HCMV (200 MOI). $3 \mathrm{~d}$ after infection, the cells were changed to serum free medium. $24 \mathrm{~h}$ later, for the uptake studies, the infected and noninfected cells were incubated for $4 \mathrm{~h}$ with $5 \mu \mathrm{g} / \mathrm{ml}$ human ${ }^{125} \mathrm{I}-\mathrm{Ox}$-LDL or ${ }^{125} \mathrm{I}$-Ac-LDL. Cells were washed three times with serum-free media and once with PBS, and then dissolved in $0.1 \mathrm{~N} \mathrm{NaOH}$ before counting. For competition studies, unlabeled oxidized or acetylated LDL (Biomedical Technologies Inc.), or native LDL freshly isolated from random donors as described previously (26) (all at 40-fold excess), or fucoidin (Sigma Chemical Co.) $25 \mu \mathrm{g} / \mathrm{ml}$ were added. For lipoprotein degradation assays, cells were incubated with ${ }^{125} \mathrm{I}-\mathrm{Ox}-\mathrm{LDL}$ as described and allowed to incubate for $8 \mathrm{~h}$. The cell medium was then collected, centrifuged, and the trichloroacetic acidsoluble lipoprotein degradation products quantitated as described (27).

Binding of acetylated $L D L$ at $4^{\circ} \mathrm{C}$. We next sought to ascertain whether the increased uptake of modified LDL observed in infected cells was a result of increased surface binding. Rat SMCs were either infected or not infected with HCMV (200 MOI). 4 d after infection, the cells were incubated with fluorescently labeled DiI-Ac-LDL at $4^{\circ} \mathrm{C}$, with or without an excess of unlabeled Ac-LDL, for $2 \mathrm{~h}$, and then washed and fixed using the same procedures as above. Binding was visualized using a scanning confocal microscope (Leica Inc., Deerfield, IL).

Transfection and SR promoter activity. HeLa cells were cotransfected with a plasmid (FXH, a gift of C.K. Glass, Department of Medcine, University of California, San Diego, CA, reference 28 ) of $\sim 5 \mathrm{~kb}$ containing the promoter and regulatory elements of the scavenger receptor class A gene upstream of a human growth hormone (HGH) reporter gene, along with an expression vector containing either IE72 (a gift of J.A. Nelson, Department of Immunology, The Scripps Research Institute, La Jolla, CA, reference 29), or IE 84 (a gift of E.S. 
Huang, Department of Immunology and Microbiology, University of North Carolina at Chapel Hill, Chapel Hill, NC, reference 30) or, as a control, the expression vector (pRC/RSV) without an insert. For transfection, HeLa cells were grown to $80 \%$ confluence in $10-\mathrm{cm}$ diameter culture dishes, and then transfected with the Calcium Phosphate Transfection System (GIBCO BRL, Gaithersburg, MD) according to the manufacturer's recommendations. Briefly, cells were transfected with $10 \mu \mathrm{g}$ of FXH DNA and $10 \mu \mathrm{g}$ of either the pRC/ RSV-IE72 DNA, pRC/RSV-IE84, or the control pRC/RSV plasmid. On days 3,5 , and 8 after transfection, 100- $\mu$ l aliquots of medium were taken from the transfected cells. Culture medium was changed on day 4. Relative HGH activity was determined with a radioisotopic assay kit (Human Growth Hormone Transient Gene Expression System; Nichols Institute Diagnostics, San Juan Capistrano, CA) according to the manufacturer's recommendation. The highest level of $\mathrm{HGH}$ in the medium was observed $8 \mathrm{~d}$ after transfection. $\mathrm{A}^{32} \mathrm{P}$-labeled plasmid was added in one experiment to normalize for transfection effi- ciency (31); no change in the fold increase of IE72 transactivation was observed.

\section{Results}

Effect of HCMV infection on modified LDL uptake and SR $m R N A$ expression by human aortic SMCs. Noninfected human SMCs demonstrated low grade background uptake of DiIAc-LDL (Fig. $1 A$ ); a similarly low basal rate of modified LDL uptake has been previously observed in SMCs from other species (32). In contrast, $4 \mathrm{~d}$ after infection with HCMV (5 MOI), uptake of DiI-Ac-LDL was markedly increased (Fig. $1 B$ ). We next sought to determine whether the increased uptake of DiIAc-LDL observed after HCMV infection was accompanied by changes in the level of transcripts encoding the scavenger re-
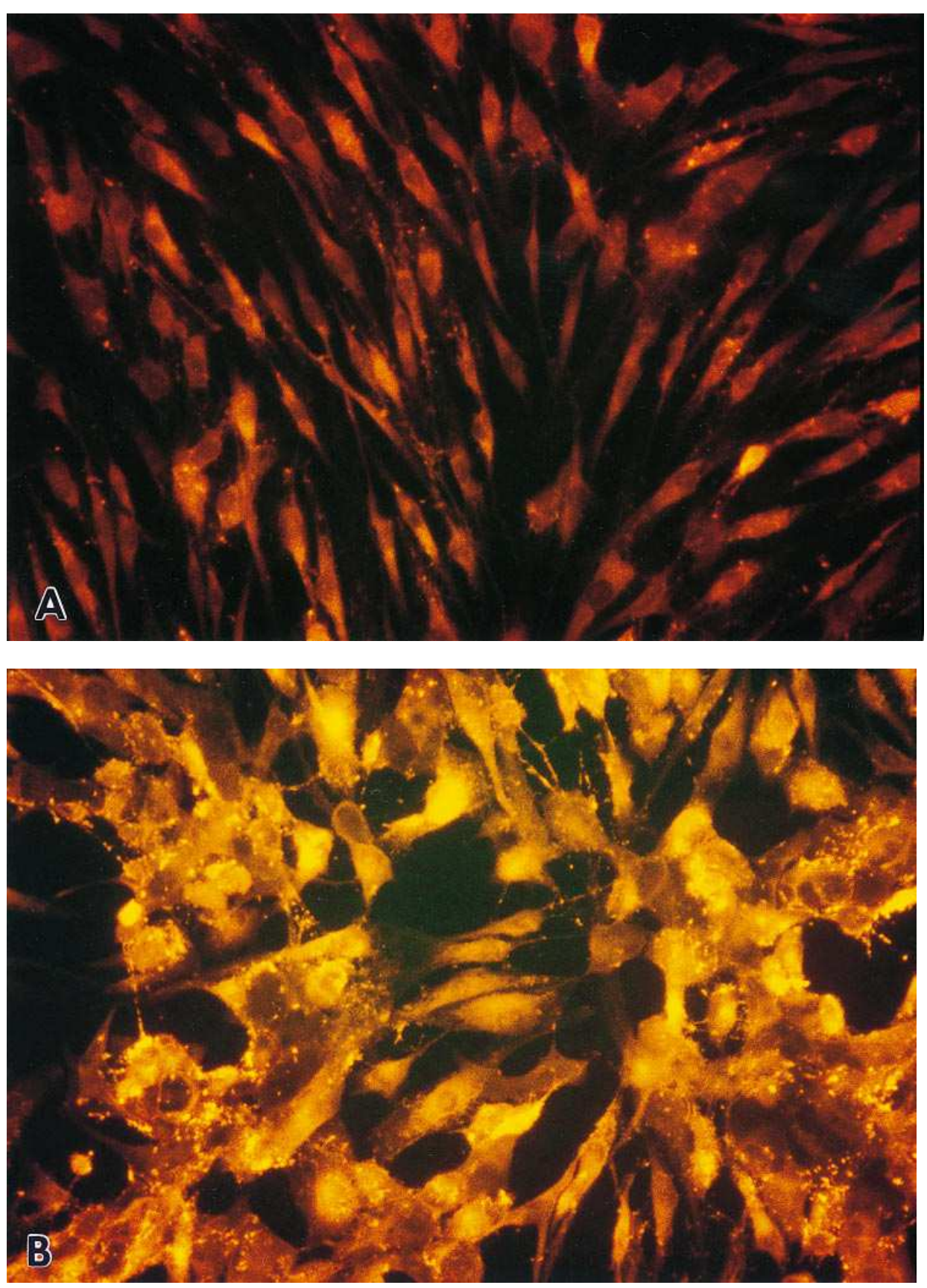

Figure 1. Acetylated LDL uptake of human aortic SMCs. $(A)$ Fluorescent micrography of uninfected human SMCs incubated with DiI-Ac-LDL. (B) Fluorescent micrography of human SMCs infected $4 \mathrm{~d}$ earlier with HCMV (5 MOI) and incubated with DiI-Ac-LDL. 

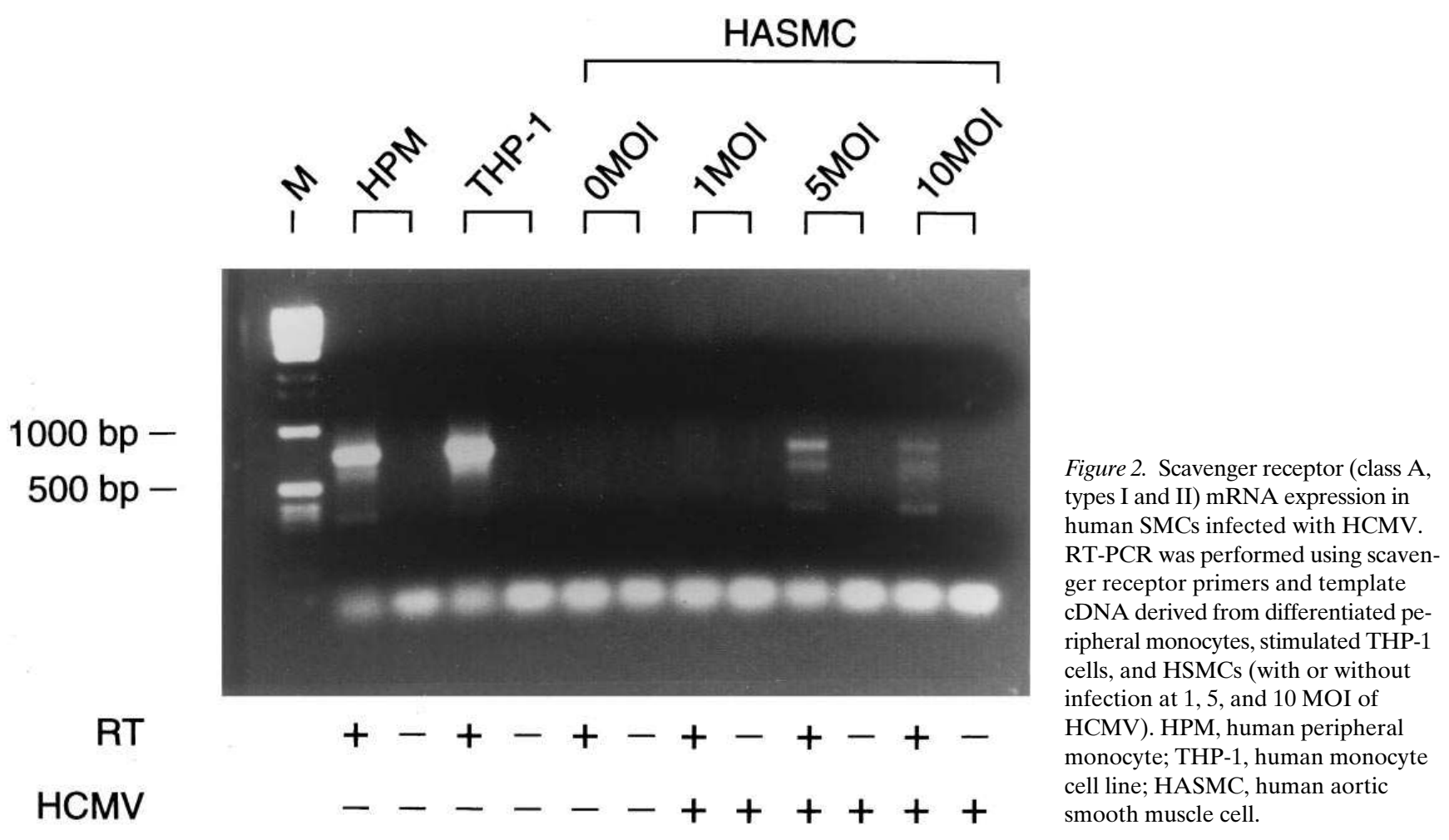

ceptor. RNA was isolated from infected and noninfected human aortic SMCs and RT-PCR was performed by using unique primers derived from the known human macrophage scavenger receptor gene (class A, types I and II). The appropriate size product was detected in SMCs infected at 5 and 10 MOI (Fig. 2), and confirmed as scavenger receptor mRNA by DNA sequencing. No signal was observed in either noninfected SMCs or in cells infected at 1 MOI. A similar size product was observed in the monocyte cell line THP-1 stimulated by phorbol esters, and in human peripheral monocytes induced to differentiate. The predicted fragment requires the addition of reverse transcriptase, consistent with amplification from RNA. Three bands were routinely seen on amplification of macrophage and SMC cDNA. The upper band was the expected size and was subcloned and sequenced to confirm its identity. The lower bands of $\sim 650$ and $450 \mathrm{bp}$ are thought to represent uncharacterized splice variants of the scavenger receptor gene.

HCMV infection of rat SMCs. Human SMCs are permissive for HCMV; hence, infection is soon followed by CPE. We therefore sought to develop a model of abortive HCMV infection, in which only IE gene products are expressed in the absence of viral replication and CPE. We found that infection of rat SMCs with HCMV provided us with the model we desired. Approximately $30-40 \%$ of the rat SMCs expressed HCMV IE72 (Fig. 3, $A$ and $B$ ) and IE84 (data not shown) protein. However, no early or late gene products were identified at this or later time points and no cytopathic effects were noted.

Experiments assessing the time course of IE gene expression, determined by examining the results of individual experiments performed at different times after infection, demonstrated that peak expression occurred on day 3, gradually decreasing to baseline over the next 2 wk (Fig. 4). This model, HCMV infection of rat SMCs, therefore allowed us to investi- gate, in the absence of cytopathic effects, the effects of HCMV on scavenger receptor activity of SMCs; it also permitted us to determine whether expression of IE gene products alone are sufficient to produce the HCMV-induced increase in SMC scavenger receptor activity.

Effects of HCMV infection on DiI-Ac-LDL uptake of rat SMCs and colocalization of DiI-Ac-LDL and IE gene products. HCMV-infected rat cells markedly increased uptake of DiI-Ac-LDL (Fig. $5 A$ ), compared with the usual background staining seen in noninfected SMCs (Fig. 5 B). Fluorescence intensity peaked at 3-5 d and gradually decreased over the following days. This particular pattern is comparable to the timing of IE viral gene expression (Fig. 4). Analysis of the doubly immunofluorescent labeled cells revealed that cells showing intense uptake of DiI-Ac-LDL were the same cells that expressed IE72 (Fig. 5, $C-E$ ).

Quantitation of modified LDL uptake of rat SMCs after HCMV infection. ${ }^{125} \mathrm{I}-\mathrm{Ox}-\mathrm{LDL}$ uptake was consistently higher (in four separate experiments, each performed in triplicate) in infected vs. noninfected SMCs (Fig. $6 A$ ). The difference observed underestimates the effects of HCMV infection on an individual cell since, under the experimental conditions employed, only $30-40 \%$ of the cells were expressing IE gene products (Fig. $3 A$ ). The uptake was blocked by the fungal polysaccharide fucoidin, a known scavenger receptor competitive inhibitor, and by a 40-fold excess of unlabeled oxidized LDL or unlabeled acetylated LDL, but not by native LDL. Similar results were observed for ${ }^{125} \mathrm{I}-\mathrm{Ox}$-LDL degradation (Fig. $6 \mathrm{~B}$ ), a finding confirming that the Ox-LDL was actually internalized and metabolized by the SMCs. ${ }^{125}$ I-Ac-LDL uptake was also higher in infected than in noninfected SMCs and was blocked by 40 -fold excess of unlabeled Ac-LDL or unlabeled Ox-LDL by fucoidin, but not by native LDL (Fig. $6 C$ ).

It is worth noting that the increase in Ox-LDL degradation 

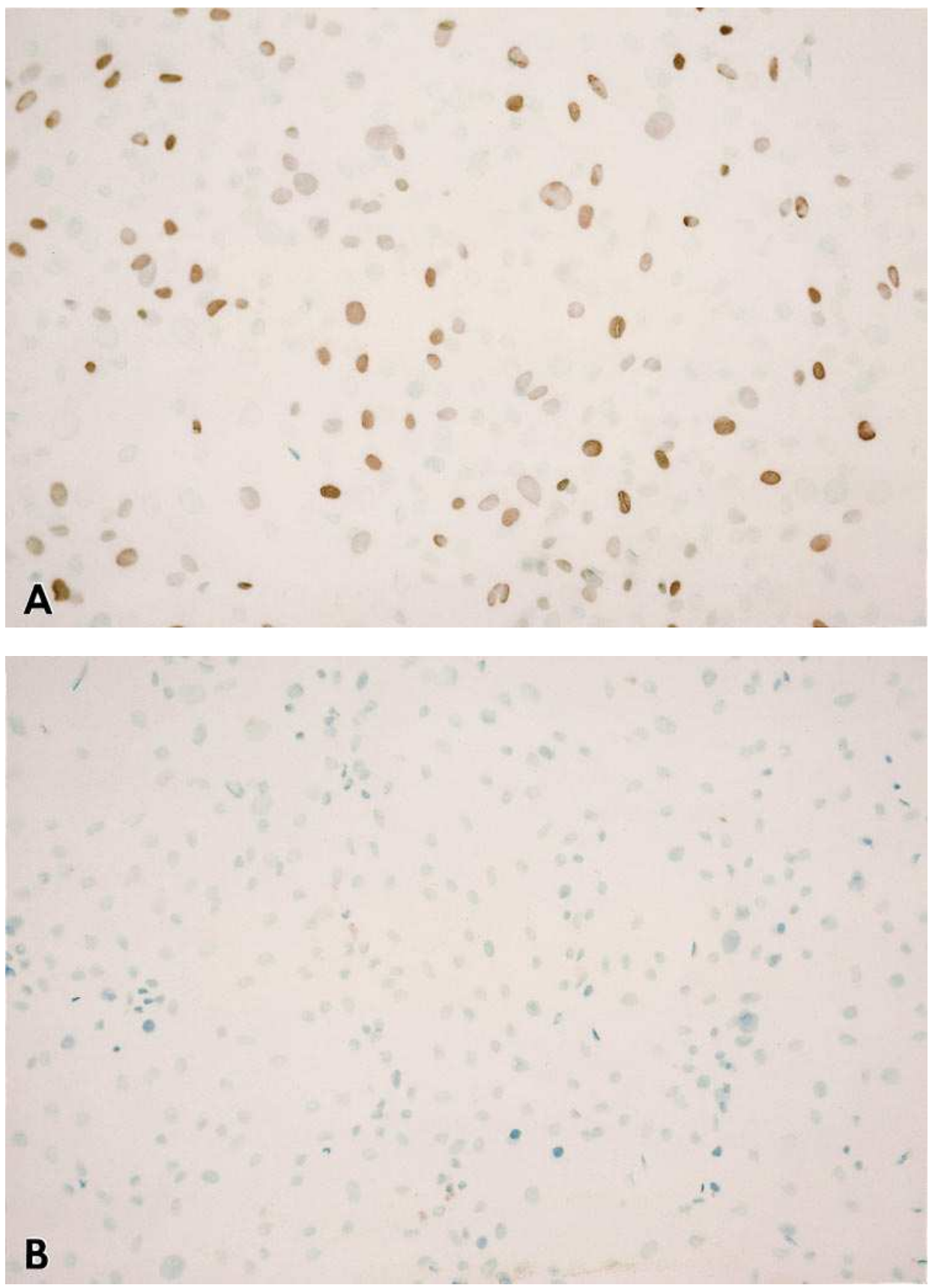

Figure 3. Expression of HCMV IE gene products in rat SMCs. $(A) \mathrm{Im}-$ munoperoxidase staining $3 \mathrm{~d}$ after infection demonstrating the nuclear localizing IE72 gene product of CMV. Immunonegative cells are indicated by methyl green counterstain. (B) Lack of positive IE72 staining in uninfected cultures.

was considerably greater than the increase in Ox-LDL uptake after CMV infection of SMCs. Among the possible explanations for this finding is that the abortive CMV infection could affect intracellular cholesterol metabolism, as has been demonstrated to occur with other herpesviruses during permissive infection of SMCs $(10,11)$.

A dose-response relation of ${ }^{125} \mathrm{I}-\mathrm{Ox}-\mathrm{LDL}$ and ${ }^{125} \mathrm{I}-\mathrm{Ac}-\mathrm{LDL}$ uptake of rat SMCs was found when cells were infected with HCMV at 50, 100, and 200 MOI (Fig. 6 D).

Binding of $A c-L D L$ at $4^{\circ} C$. $4 \mathrm{~d}$ after infection with HCMV, infected and noninfected cells were incubated at $4^{\circ} \mathrm{C}$ with DiIAc-LDL, and subsequently visualized by fluorescence microscopy. In infected cells, binding at $4^{\circ} \mathrm{C}$ was similar to what we observed with uptake of DiI-Ac-LDL at $37^{\circ} \mathrm{C}$, in that $\sim 20$
$25 \%$ of infected rat SMCs demonstrated activity (Fig. $7 B$ ). There was little binding to noninfected cells (Fig. $7 A$ ), or to infected cells in the presence of excess unlabled Ac-LDL (Fig. $7 C)$.

Effect of HCMV immediate-early gene products on scavenger receptor promoter activity. We next sought to assess whether the immediate-early genes of HCMV (IE72 or IE84) could directly transactivate the scavenger receptor promoter. Transient cotransfection of the scavenger receptor promoterHGH reporter gene plasmid and an IE72 expression vector into HeLa cells led to a 3.7-fold increase of secreted $\mathrm{HGH}$ activity over that obtained from cells transfected with the reporter gene construct and the expression vector alone (Fig. 8). Cotransfaction of an IE84 expression vector with the reporter 


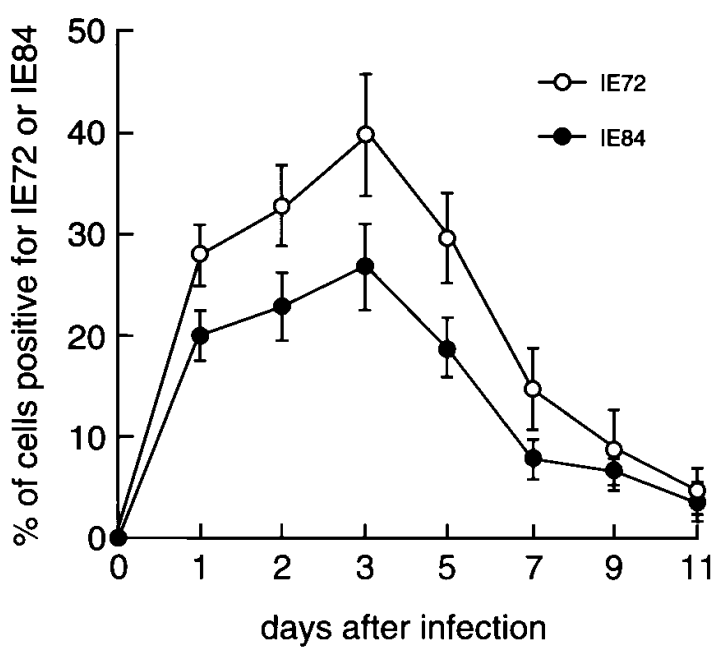

Figure 4. Time course of HCMV IE72 and IE84 expression in rat SMCs. Cells were seeded, cultured, and infected in eight-well chamber slides and assayed for IE72 and IE84 gene expression by immunoperoxidase staining at days $1-3,5,7,9$, and 11 after HCMV infection. Three different high power fields were examined in each of three separate slides obtained at each time point to determine the expression of IE72 and IE84. Approximately 50 cells per high power field were counted and the data were expressed as percent positive cells (mean $\pm \mathrm{SD})$.

gene construct did not increase baseline transcriptional activity.

\section{Discussion}

Human cytomegalovirus is a ubiquitous virus, with a majority of the adult population exhibiting evidence of prior infection (33). HCMV, like other herpesviruses, remains in the host in a latent state for life (34). It is generally believed that, with the exception of immunocompromised subjects such as patients with AIDS or patients on immunosuppressive therapy, HCMV does not cause serious disease. Such a belief may be incorrect, however, as an increasing body of information is accumulating suggesting that HCMV may participate in the development of atherosclerosis (35) and of restenosis after coronary angioplasty (36-38). The results of the present investigation, demonstrating that HCMV infection of human aortic SMCs increases uptake of Ox-LDL (Fig. 1) provide further data suggesting that HCMV may indeed contribute to the processes leading to atherosclerosis.

Human SMCs are permissive for HCMV; IE, early, and late gene products are expressed, followed by viral replication and cytopathic effect. However, with human CMV infection of rat SMCs, only IE genes of CMV are expressed. In this model, we found that IE gene expression alone is sufficient to increase uptake of both Ox- and Ac-LDL (Fig. 6). The causal role of IE gene expression on increased modified LDL uptake in this model was further suggested by the observation that the time course of modified LDL uptake coincides with the time course of IE viral gene expression (Fig. 4), and that the cells taking up modified LDL were the same cells that expressed the IE gene products of HCMV (Fig. 5, $C-E$ ). HCMV infection of rat SMCs also increased ${ }^{125}$ I-Ox-LDL degradation, and caused an increase in Ac-LDL binding at $4^{\circ} \mathrm{C}$ (Fig. 7), findings confirm- ing that HCMV-induced increase in Ox-LDL uptake actually reflects Ox-LDL internalized and metabolized by the SMCs, and that the effects are most likely receptor mediated.

Although active viral infection and viral replication can exert important pathophysiologic effects, herpesviruses, such as herpes zoster, herpes simplex, and Ebstein-Barr viruses, also contribute to disease processes during abortive infections, which are characterized by viral gene expression limited to IE gene products and the absence of viral replication (39). A similar role of abortive infection in human disease has been suggested for HCMV. In particular, HCMV IE gene products are known to affect the expression of many human cellular genes involved in inflammatory and immune responses, and our finding that IE84 binds to and inhibits p53 (36) further suggests that an abortive HCMV infection may, in itself, cause critical cellular changes that could contribute to atherogenic-related processes. The current findings provide futher evidence supporting the concept that abortive infection with HCMV may contribute to atherogenesis.

Modified LDL is taken up by cells via receptors initially refered to as "the scavenger receptor" (16). cDNAs encoding two related forms of bovine scavenger receptor were first cloned in $1990(40,41)$, followed in several years by the cloning of the human homologues (42). The two homologous isoforms, arising from alternative splicing of a single gene, consist of novel, highly conserved, trimeric membrane-spanning proteins. These proteins have more recently been termed class A SR gene products (types I and II), hereafter referred to as SR-A (40-45).

Recently, additional receptors capable of binding and internalizing Ox-LDL have been identified, including CD36 (46), Fc $\gamma$ RII-B2 (47), a 94-kD protein (48) and SR-B1 (a class B scavenger receptor that has recently been identified as also having the capacity to bind high density lipoprotein, reference 49). The biological roles of these more newly described receptors, and how their roles compare with that of the SR-A are as yet undefined. However, the receptors are sufficiently different in structure and physiologic function so that experimental strategies may be used to distiguish which of these particular receptors are likely to be playing a role under specific experimental conditions. Thus, whereas class A SRs recognize both oxidized and acetylated LDL, the more newly described receptors are relatively specific for Ox-LDL. This accounts for the observation that, although excess acetylated LDL can block uptake of Ox-LDL by class A SRs, it does not efficiently block Ox-LDL uptake by the other receptors $(47,50)$.

We therefore undertook additional studies to further characterize the HCMV-induced increase in modified LDL uptake. HCMV infection of rat SMCs increased both ${ }^{125}$ I-ox-LDL and ${ }^{125}$ I-Ac-LDL uptake; the increased uptake of each ligand was blocked by an excess of either cold Ox- or Ac-LDL (Fig. 6). It was also blocked by fucoidin (an SR ligand that competes for SR binding with other SR ligands) but not by native LDL (Fig. 6). Thus, the receptor involved in the increase in SR activity after CMV infection has the functional characteristics of the class A (types I and II) SR. That this particular SR participates in the increased uptake of modified LDL after CMV infection is further evidenced by our RT-PCR experiments. Using primers derived from SR-A mRNA, although undetectable in noninfected SMCs, was present in infected human SMCs (Fig. 2).

It should also be pointed out that under baseline conditions 

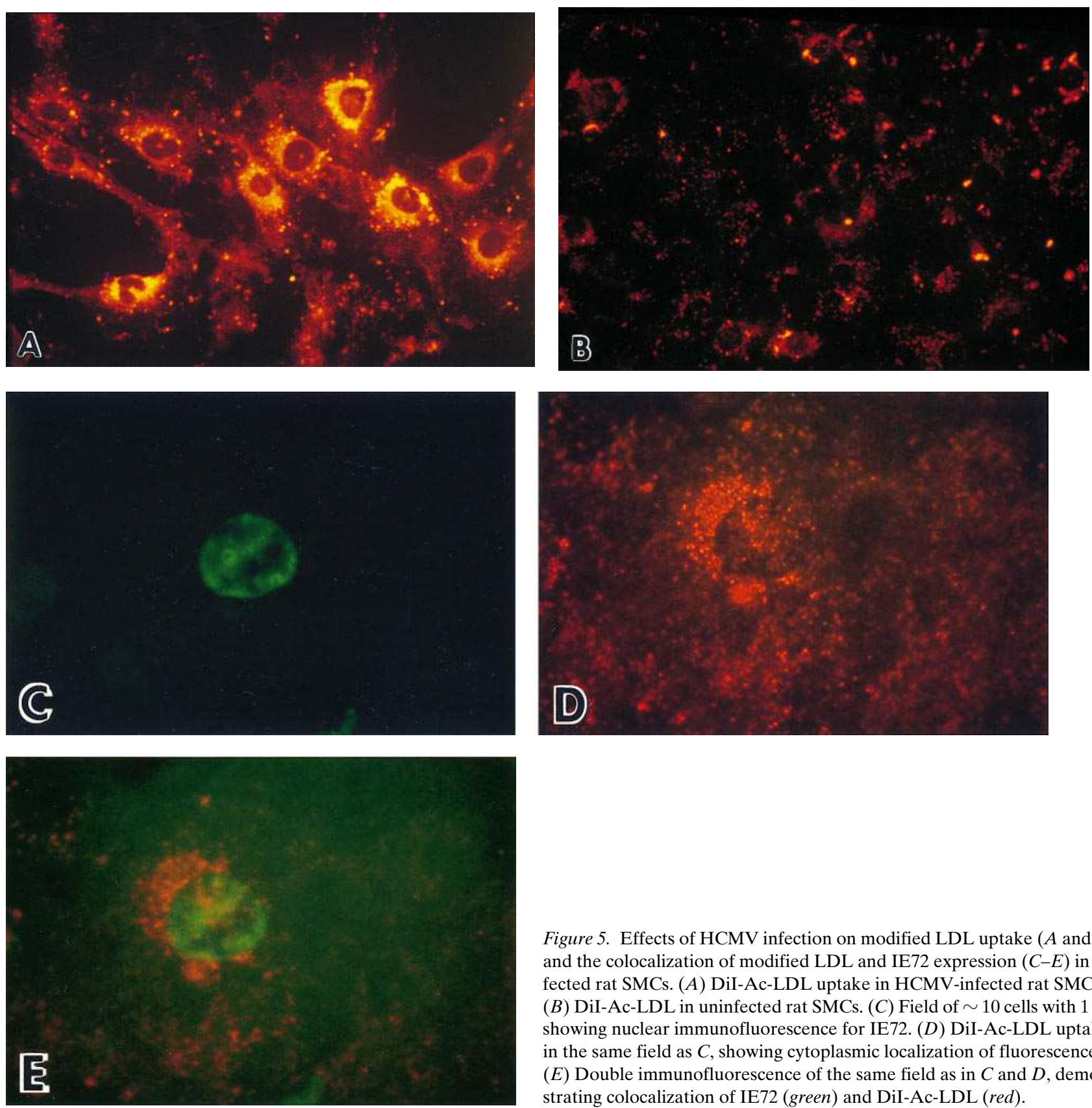

Figure 5. Effects of HCMV infection on modified LDL uptake ( $A$ and $B$ ), and the colocalization of modified LDL and IE72 expression $(C-E)$ in infected rat SMCs. (A) DiI-Ac-LDL uptake in HCMV-infected rat SMCs. (B) DiI-Ac-LDL in uninfected rat SMCs. (C) Field of $\sim 10$ cells with 1 cell showing nuclear immunofluorescence for IE72. (D) DiI-Ac-LDL uptake in the same field as $C$, showing cytoplasmic localization of fluorescence. $(E)$ Double immunofluorescence of the same field as in $C$ and $D$, demonstrating colocalization of IE72 (green) and DiI-Ac-LDL (red).

a scavenger receptor with the functional characteristics of SR-A is active in rat SMCs, a situation that appears to differ from that of human SMCs, insofar as in human SMCs, no SR-A mRNA can be detected under baseline conditions, even with RT-PCR.

Although expression of the SR-A was initially believed to be limited to macrophage-related cell types, cDNAs of SR-A have been cloned from a cDNA library prepared from phorbolester-treated rabbit SMCs $(51,52)$. Their expression in rabbit SMCs is induced by cytokines, phorbolesters, serum, thrombin, and platelet-secretory products, and expression in human and rabbit SMCs is synergistically enhanced by exposure to PDGF BB, EGF, IGF-I, and TGF- $\beta_{1}(53,54)$. In addition, considerable information is accumulating regarding regulation of SR-A expression. Thus, Wu et al. (28) have shown that the scavenger receptor A gene that encodes these receptors is upregulated during differentiation of monocytes to macrophages, considerable progress has been made in identifying factors that bind to upstream regulatory sequences.

In the course of our studies, we demonstrated that after CMV infection of SMCs, IE gene expression peaks on day 3 and subsides to baseline within 1-2 wk. If viral IE gene expression is relevant to the long term progression of atherosclerosis, the question arises as to whether there is a mechanism whereby latent CMV infection of a host results in either sustained IE gene expression or repeated episodes of gene expression over time. Although there is no direct evidence that this occurs with latent CMV infection, there is a large body of data that at least indirectly suggests that this is indeed the case. Thus, CMV is reactivated from latency when the immune sys- 

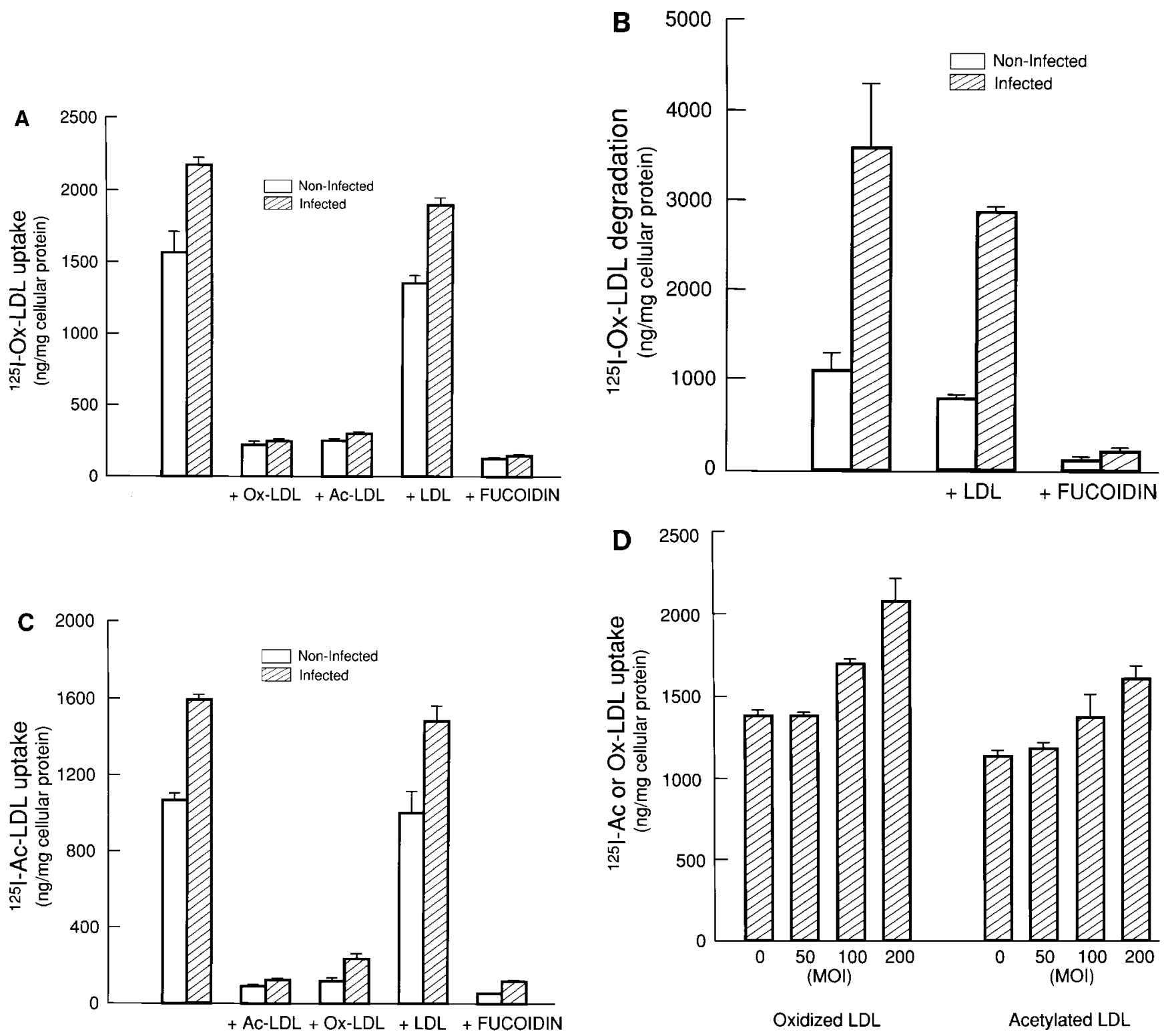

Figure 6. Increased uptake of ${ }^{125} \mathrm{I}$-Ox-LDL and ${ }^{125} \mathrm{I}-\mathrm{Ac}-\mathrm{LDL}$ after HCMV infection. $(A)$ Uptake of ${ }^{125} \mathrm{I}-\mathrm{Ox}$-LDL in uninfected and infected rat SMC cultures in the presence or absence of a 40-fold excess of unlabeled oxidized LDL $(+O x-L D L)$, unlabeled acetylated LDL $(+A c-L D L)$, or of unlabeled native LDL, and in the presence of the scavenger receptor competitive inhibitor fucoidin. (B) Degradation of ${ }^{125} \mathrm{I}-\mathrm{Ox}$-LDL in infected and uninfected cultures. $(C)$ Uptake of ${ }^{125} \mathrm{I}$-Ac-LDL in uninfected and infected rat SMC cultures in the presence or absence of a 40-fold excess of unlabeled acetylated LDL (+Ac- $L D L)$, unlabled oxidized LDL $(+O x-L D L)$, or of unlabeled native LDL, and in the presence of the scavenger receptor competitive inhibitor fucoidin. $(D)$ Effects of HCMV infection of rat SMC at different MOI on uptake of oxidized (left) or acetylated (right) LDL. All experiments were performed in triplicate and expressed as mean \pm SD.

tem of the host is compromised, such as in AIDS and in transplantation patients undergoing immunosupressive therapy. It is possible that less extreme conditions can also reactivate the virus from latency, as occurs with other herpesviruses such as herpes simplex, herpes zooster, and Ebstein-Barr viruses. These viruses reside in the host in a latent state and are periodically reactivated by unknown stimuli to produce clinically evident disease.

We have recently demonstrated that reactive oxygen species cause activation of the major immediate early promoter of the virus and are necessary for viral replication in infected SMCs (55). We have also recently shown that Ox-LDL, in the presence of SMCs or endothelial cells, activates the immediate early promoter of the virus (56). These observations lend further credence to the hypothesis that CMV, present in a latent state in cells of the vessel wall, is periodically reactivated and, through several putative mechanisms, including the one proposed in the present investigation, may thereby contribute to the long term progression of atherosclerosis.

In conclusion, our results indicate that HCMV infection increases uptake of Ox-LDL by vascular SMCs. The increased uptake appears to be caused by increased class A scavenger receptor gene expression, an effect mediated, at least in part, by the virus's immediate-early gene product, IE72. Thus, HCMV can increase the capacity of SMCs to incorporate Ox-LDL, and can do so in the absence of viral replication. This finding is 

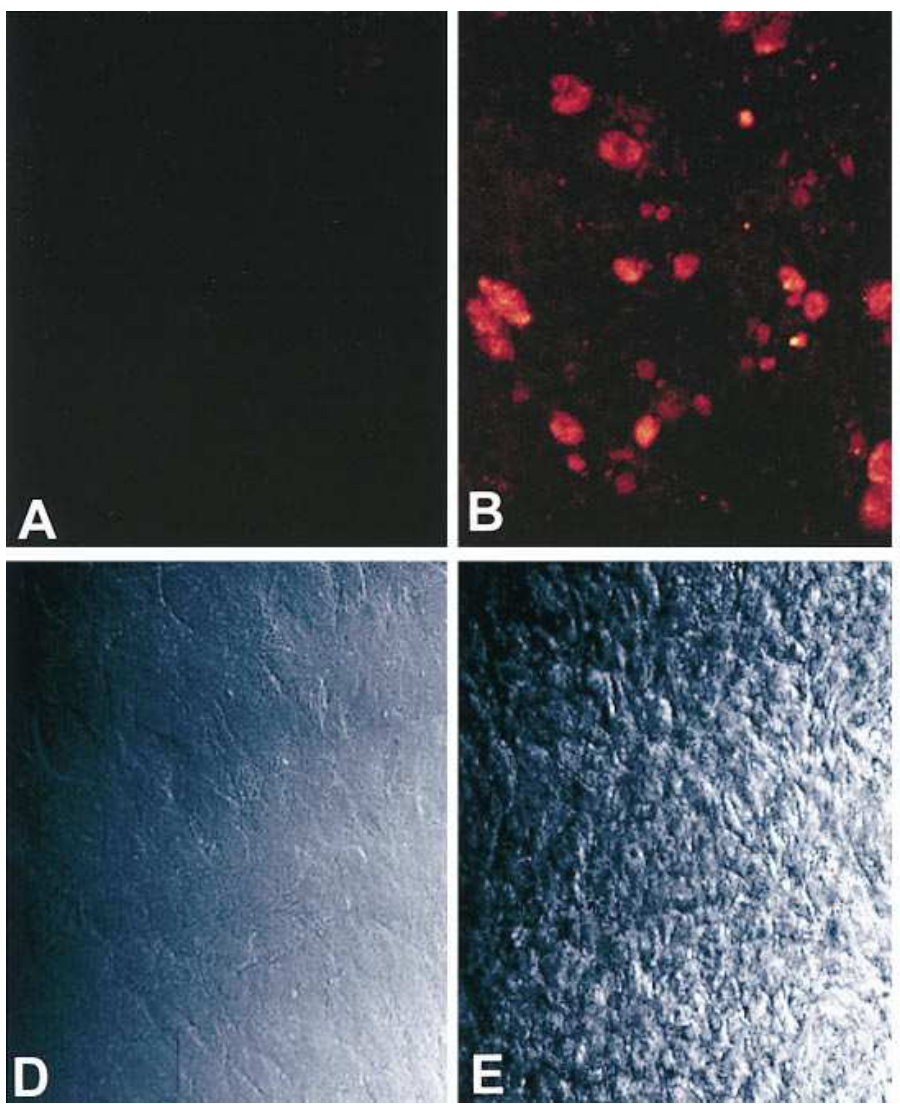
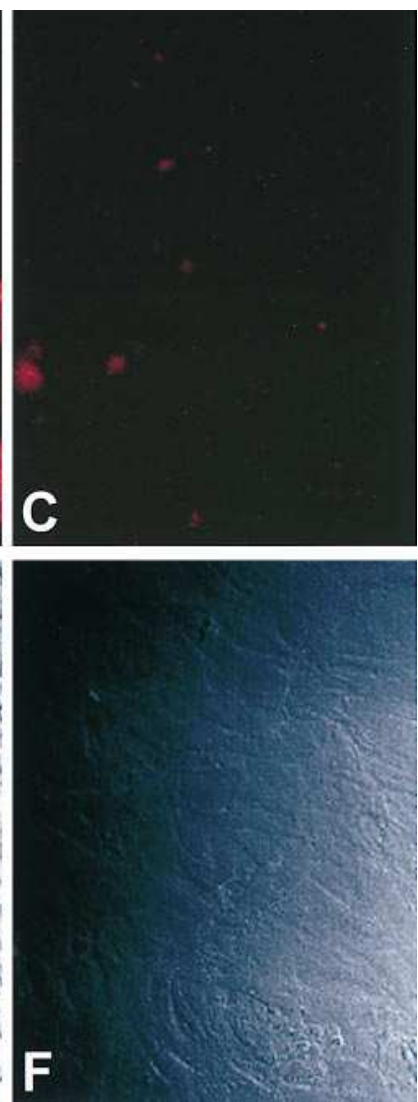

Figure 7. Acetylated LDL uptake of rat SMCs at $4^{\circ} \mathrm{C}$. Fluorescence micrographs $(A-C)$ and corresponding phase contrast micrographs $(D-F) .(A)$ Uninfected cells incubated with DiI-Ac-LDL. (B) Cells infected $4 \mathrm{~d}$ earlier with HCMV (200 MOI) and incubated with DiI-Ac-LDL. The number of fluorescent cells represented $\sim 20-25 \%$ of cells present in the field. $(C)$ Fluorescent micrography of infected cells incubated with DiI-Ac-LDL plus 40 times excess unlabeled acetylated LDL. consistent with the known propensity of herpesviruses to exert cellular effects during abortive, nonpermissive infections. Because HCMV also encodes an IE protein (IE84) that, by interfering with the inhibitory actions of $\mathrm{p} 53$, can predispose to SMC accumulation, it appears that HCMV possesses the genetic programs that can alter the function of infected SMCs so that two of the major mechanisms underlying atherogenesis are activated, increased SMC accumulation, and increased uptake of Ox-LDL. Given the epidemiologic and experimental data outlined above, the results of the present investigation

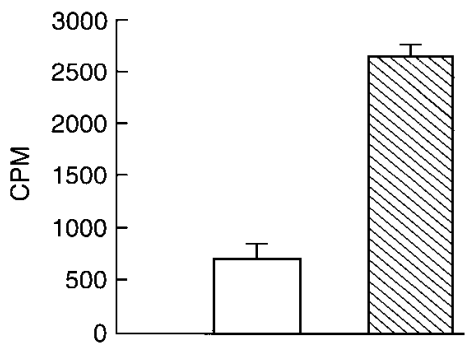

Figure 8. Effect of transient transfection of the IE72 gene on human scavenger receptor (class A, types I and II) promotor activity. HeLa cells were cotransfected with a scavenger receptor promoterHGH reporter plasmid and either an expression vector containing IE72

(shaded bar) or the expression vector alone (open bar). The amount of $\mathrm{HGH}$ in the medium was determined using a ${ }^{125} \mathrm{I}$-labeled $\mathrm{HGH}$ monoclonal antibody. The assay involved a modified radioimmunoassay in which the measured activity (CPM) is proportional to the concentration of $\mathrm{HGH}$ in the medium, and hence to promoter activity. One representative transfection performed in quadruplicate from three similar experiments is shown. Results were obtained from quadruplicate samples and expressed as mean \pm SD. provide mechanistic support for the hypothesis that HCMV predisposes to the development of atherosclerosis.

\section{Acknowledgments}

The authors thank C. Glass and J. Nelson for generous gifts of plasmids, E.S. Huang for his invaluable advice and guidance and his gifts of plasmids, B. Brewer for helpful advice, and D. Koch for expert preparation of this manuscript.

\section{References}

1. Bruggeman, C.A., and M.C.E. Van Dam-Mieras. 1991. The possible role of cytomegalovirus in atherogenesis. Prog. Med. Virol. 38:1-26.

2. Melnick, J.L., E. Adam, and M.E. Debakey. 1993. Cytomegalovirus and atherosclerosis. Eur. Heart J. 14(Suppl. K):30-38.

3. Hendrix, M.G.R., M. Daemen, and C.A. Bruggeman. 1991. Cytomegalovirus nucleic acid distribution within the human vascular tree. Am. J. Pathol. 138:563-567.

4. Melnick, J.L., C. Hu, J. Burek, E. Adam, and M.E. Debakey. 1994. Cytomegalovirus DNA in arterial walls of patients with atherosclerosis. J. Med. Virol. 42:170-174.

5. Loebe, M., S. Schuler, O. Zais, H. Warnecke, E. Fleck, and R. Hetzer. 1990. Role of cytomegalovirus infection in the development of coronary artery disease in the transplanted heart. J. Heart Transplant. 9:707-711.

6. Grattan, M.T., C.E. Moreno-Cabral, V.A. Starnes, P.E. Oyer, E.B. Stinson, and N.E. Shumway. 1989. Cytomegalovirus infection is associated with cardiac allograft rejection and atherosclerosis. JAMA (J. Am. Med. Assoc.) 261: 3561-3566.

7. Melnick, J.L., E. Adam, and M.E. DeBakey. 1990. Possible role of cytomegalovirus in atherosclerosis. JAMA (J. Am. Med. Assoc.). 263:2204-2207.

8. Fabricant, C.G., J. Fabricant, M.M. Litrenta, and C.R. Minick. 1978. Virus-induced atherosclerosis. J. Exp. Med. 148:335-340.

9. Minick, C.R., C.G. Fabricant, J. Fabricant, and M.M. Litrenta. 1979. Atheroarteriosclerosis induced by infection with a herpes virus. Am. J. Pathol. 96:673-706.

10. Hajjar, D.P., C.G. Fabricant, C.R. Minick, and J. Fabricant. 1986. Virus- 
induced atherosclerosis: herpesvirus infection alters aortic cholesterol metabolism and accumulation. Am. J. Pathol. 122:62-70.

11. Hajjar, D.P. 1986. Herpesvirus infection prevents activation of cytoplasmic cholesteryl esterase in arterial smooth muscle cells. J. Biol. Chem. 261: 7611-7614.

12. Steinberg, D. 1991. Lipoprotein modification and atherogenesis. Atheroscler. Rev. 23:115-121.

13. Brown, M.S., and J.L. Goldstein. 1984. How LDL receptors influence cholesterol and atherosclerosis. Sci. Am. 251:58-66.

14. Gil, G., T.F. Osborne, J.L. Goldstein, and M.S. Brown. 1988. Purification of a protein doublet that binds to six TGG-containing sequences in the promoter for hamster 3-hydroxy-3-methylglutaryl-COA-reductase. J. Biol. Chem. 263:19009-19019.

15. Leake, D.S., and S.M. Rankin. 1990. The oxidative modification of low density lipoproteins by macrophages. Biochem. J. 270:741-748.

16. Goldstein, J.L., Y.K. Ho, S.K. Basu, and M.S. Brown. 1979. Binding site on macrophages that mediates uptake and degradation of acetylated low density lipoprotein, producing massive cholesterol deposition. Proc. Natl. Acad. Sci. USA. 76:333-337.

17. Yla-herttuala, S., M.E. Rosenfeld, S. Parthasarathy, E. Sigal, T. Sarkioja, J.L. Witztum, and D. Steinberg. 1991. Gene expression in macrophage-rich human atherosclerotic lesions. 15-Lipoxygenase and acetyl low density lipoprotein receptor messenger RNA colocalize with oxidation specific lipid-protein adducts. J. Clin. Invest. 87:1146-1152.

18. Freeman, M., Y. Ekkel, L. Rohrer, M. Penman, N.J. Freedman, G.M. Chisolm, and M. Krieger. 1991. Expression of type I and type II bovine scavenger receptors in Chinese hamster ovary cells: lipid droplet accumulation and nonreciprocal cross competition by acetylated and oxidized low density lipoprotein. Proc. Natl. Acad. Sci. USA. 88:4931-4935.

19. Wolle, S., D.P. Via, L. Chan, J.A. Cornicelli, and C.L. Bisgaier. 1995. Hepatic overexpression of bovine scavenger receptor type I in transgenic mice prevents diet-induced hyperbetalipoproteinemia. J. Clin. Invest. 96:260-272.

20. Brown, M.S., and J.L. Goldstein. 1990. Scavenging for receptors. Nature (Lond.). 343:508-509.

21. Campbell, J.H., and G.R. Campbell. 1987. Methods of growing vascular smooth muscle in culture. In Vascular Smooth Muscle in Culture. J.H. Campbell, and G.R. Campbell, editors. CRC Press Inc., Boca Raton, FL. 15-21.

22. Watanabe, Y., T. Inaba, H. Shimano, T. Gotoda, K. Yamanoto, H. Mokuno, H. Sato, Y. Yazaki, and N. Yamada. 1994. Induction of LDL receptorrelated protein during the differentiation of monocyte-macrophages: possible involvement in the atherosclerotic process. Arterioscler. Thromb. 14:1000-1006.

23. Ballew, H.C. 1992. Neutralization. In Clinical Virology Manual. S. Specter, and G. Lancz, editors. Elsevier Science Publishing Co., New York. 229-241.

24. Matsumoto, A., M. Naito, H. Itakura, S. Ikemoto, H. Asaoka, I. Hayakawa, H. Kanamori, H. Aburatani, F. Takaku, H. Suzuki, Y. Kobari, T. Miyai, K. Takahashi, E.H. Cohen, R. Wydro, D.E. Housman, and T. Kodama. 1990. Human macrophage scavenger receptors: primary structure, expression, and localization in atherosclerotic lesions. Proc. Natl. Acad. Sci. USA. 87:9133-9137.

25. Weinshenker, B.G., S. Wilton, and G.P.A. Rice. 1988. Phorbol esterinduced differentiation permits productive human cytomegalovirus infection in a monocytic cell line. J. Immunol. 140:1625-1631.

26. Sack, M.N., D.J. Rader, and R.O. Cannon. 1994. Oestrogen and inhibition of oxidation of low-density lipoproteins in postmenopausal women. Lancet (N. Am. Ed.). 343:269-270.

27. Goldstein, J.L., S.K. Basu, and M.S. Brown. 1983. Receptor-mediated endocytosis of low-density lipoprotein in cultured cells. Methods Enzymol. 98: 241-260

28. Wu, H., K. Moulton, A. Horvai, S. Parik, and C.K. Glass. 1994. Combinatorial interactions between AP-1 and ets domain proteins contribute to the developmental regulation of the macrophage scavenger receptor gene. Mol. Cell. Biol. 14:2129-2139.

29. Ghazal, P., J. Young, E. Giulietti, C. Demattei, J. Garcia, R. Gaynor, R.M. Stenberg, and J.A. Nelson. 1991. A discrete cis element in the human immunodeficiency virus long terminal repeat mediates synergistic trans activation by cytomegalovirus immediate-early proteins. J. Virol. 65:6735-6742.

30. Yurochko, A., T.F. Kowalik, S.M. Huong, and E.S. Huang. 1995. Hu-

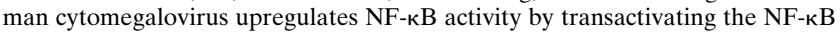
p105/p50 and p65 promoters. J. Virol. 69:5391-5400.

31. Stein, J., H.D. Volk, C. Liebenthal, D.H. Kruger, and S. Prosch. 1993. Tumour necrosis factor $\alpha$ stimulates the activity of the human cytomegalovirus major immediate early enhancer/promoter in immature monocytic cells. J. Gen. Viol. 74:2333-2338.

32. Pitas, R.E. 1990. Expression of the acetyl low density lipoprotein receptor by rabbit fibroblasts and smooth muscle cells. J. Biol. Chem. 265:1272212727.

33. Huang, E.S., and T. Kowalik. 1993. The pathogenicity of human cytomegalovirus. In Molecular Aspects of Human Cytomegalovirus Diseases. Y. Beker, and G. Darai, editors. Springer-Verlag, Berlin. 1-45.
34. Bruggeman, C.A. 1993. Cytomegalovirus and latency: an overview. Virchows Archiv. B Cell Pathol. 64:325-333.

35. Melnick, J.L., and M.E. Debakey. 1993. Cytomegalovirus and atherosclerosis. Eur. Heart J. 14(Suppl. K):30-38.

36. Speir, E., R. Modali, E.S. Huang, M.B. Leon, F. Shawl, T. Finkel, and S.E. Epstein. 1994. Potential role of human cytomegalovirus and p53 interaction in coronary restenosis. Science (Wash. DC). 265:391-394.

37. Zhou, Y.F, M. Shou, R. Guzman, E. Guetta, T. Finkel, and S.E. Epstein. 1995. Cytomegalovirus infection increases neointimal formation in the rat model of balloon injury. J. Am. Coll. Cardiol. (Suppl.):242a. (Abstr.)

38. Zhou, Y.F., M.B. Leon, M.A. Waclawiw, J.J. Popma, Z.X. Yu, T. Finkel, and S.E. Epstein. 1996. Association between prior cytomegalovirus infection and the risk of restenosis after coronary atherectomy. N. Engl. J. Med. 335:624-630.

39. Ho, M. 1991. Abortive, persistent, and latent infections in cell cultures. In Cytomegalovirus: Biology and Infection. Plenum Publishing Co., New York. 87-94.

40. Kodama, T., M. Freeman, L. Rohrer, J. Zabrecky, P. Matsudaira, and M. Krieger. 1990. Type I macrophage scaventer receptor contains $\alpha$-helical and collagen-like coiled coils. Nature (Lond.). 343:531-535.

41. Rohrer, L., M. Freeman, T. Kodama, M. Penman, M. Krieger. 1990. Coiled-coil fibrous domains mediate ligand binding by macrophage scavenger receptor type II. Nature (Lond.). 343:570-572.

42. Emi, M., H. Asaoka, A. Matsumoto, H. Itakura, Y. Kurihara, Y. Wada, H. Kanamori, Y. Yazaki, E. Takahashi, M. Lepert et al. 1993. Structure, organization, and chromosomal mapping of the human macrophage scavenger receptor gene. J. Biol. Chem. 268:2120-2125.

43. Horvai, A., W. Palinski, H. Wu, K.S. Moulton, K. Kalla, and C.K. Glass. 1995. Scavenger receptor A gene regulatory elements target gene expression to macrophages and to foam cells of atherosclerotic lesions. Proc. Natl. Acad. Sci. USA. 92:5391-5395.

44. Ottnad, E., S. Parthasarathy, G.R. Sambrano, M.P. Ramprasad, O. Quehenberger, N. Kondratenko, S. Green, and D. Steinberg. 1995. A macrophage receptor for oxidized low density lipoprotein distinct from the receptor for acetyl low density lipoprotein: partial purification and role in recognition of oxidatively damaged cells. Proc. Natl. Acad. Sci. USA. 92:1391-1395.

45. Sambrano, G.R., and D. Steinberg. 1995. Recognition of oxidatively damaged and apoptotic cells by an oxidized low density lipoprotein receptor on mouse peritoneal macrophages: role of membrane phosphatidylserine. Proc Natl. Acad. Sci. USA. 92:1396-1400.

46. Endemann, G., L.W. Stanton, K.S. Madden, C.M. Bryant, R.T. White, and A.A. Protter. 1993. CD36 is a receptor for oxidized low density lipoprotein. J. Biol. Chem. 268:11811-11816.

47. Stanton, L.W., R.T. White, C.M. Bryant, A.A. Protter, G. Endemann. 1992. A macrophage Fc receptor for IgG is also a receptor for oxidized low density lipoprotein. J. Biol. Chem. 267:22446-22451.

48. Ramprasad, M.P., W. Fischer, J.L. Witztum, G.R. Sambrano, O. Quehenberger, and D. Steinberg. 1995. The 94- to 97-kDa mouse macrophage membrane protein that recognizes oxidized low density lipoprotein and phosphatidylserine-rich liposomes is identical to macrosialin, the mouse homologue of human CD68. Proc. Natl. Acad. Sci. USA. 92:9580-9584.

49. Acton, S., A. Rigotti, K.T. Landschulz, S. Xu, H.H. Hobbs, and M. Krieger. 1996. Identification of scavenger receptor SR-BI as a high density lipoprotein receptor. Science (Wash. DC). 271:518-520.

50. Sparrow, C.P., S. Parthasarathy, and D. Steinberg. 1989. A macrophage receptor that recognizes oxidized low density lipoprotein but not acetylated low density lipoprotein. J. Biol. Chem. 264:2599-2604.

51. Bickel, P.E., and M.W. Freeman. 1992. Rabbit aortic smooth muscle cells express inducible macrophage scavenger receptor messenger RNA that is absent from endothelial cells. J. Clin. Invest. 90:1450-1457.

52. Dejager, S., M. Mietus-Snyder, and R.E. Pitas. 1993. Oxidized low density lipoproteins bind to the scavenger receptor expressed by rabbit smooth muscle cells and macrophages. Arterioscler. Thromb. 13:371-378.

53. Li, H., M.W. Freeman, and P. Libby. 1995. Regulation of smooth muscle cell scavenger receptor expression in vivo by atherogenic diets and in vitro by cytokines. J. Clin. Invest. 95:122-133.

54. Gong, Q., and R.E. Pitas. 1995. Synergistic effects of growth factors on the regulation of smooth muscle cell scavenger receptor activity. J. Biol. Chem. 270:21672-21678

55. Speir, E., T. Shibutani, Z.X. Yu, and S.E. Epstein. 1995. The antioxidant $\mathrm{N}$-Acetylcysteine inhibits, in vascular smooth muscle cells, cytomegalovirus replication, cytopathic effects, and activation of the cytomegalovirus promoter by IE72. Circulation. 92:I-231. (Abstr.)

56. Guetta, E., V. Guetta, and S.E. Epstein. 1995. Cytomegalovirus interaction with monocytes, endothelial cells, and oxidized low density lipoprotein-a possible model for viral reactivation and atherosclerosis development. Circulation. 92:I-161. (Abstr.) 